\title{
Psychiatry as part of a Pre-registration Rotation
}

\author{
C. P. SeAger, Professor of Psychiatry, University Department of Psychiatry, Northern General Hospital, Sheffield
}

The General Medical Council published Recommendations on Basic Medical Education ${ }^{1}$ in which the principles of the Pre-registration House Officer post were updated. An important provision was the acceptance of a variety of combinations of posts including four months in general medicine, four months in general surgery and four months in another clinical hospital discipline or in a health centre.

After considerable negotiation, the Postgraduate Dean of the Faculty of Medicine at Sheffield University agreed to the recognition of a twelve month rotation for Preregistration House Officers consisting of four months general medicine, four months general surgery and four months psychiatry. The first of these rotations started in August 1981 and a second group three years later. ${ }^{2}$

\section{Outline of scheme}

In Sheffield, medical students usually start making arrangements for House Officer posts in the December preceding their graduation in the following June. Aspirants are advised that this rotation scheme is not advisable for those students who have already decided to make a career in psychiatry. Preference is given to those who wish to have a period of graduate experience in psychiatry before making up their mind, or those who feel that such experience will be valuable to them in a career in general practice or nonpsychiatric hospital specialities. Candidates are interviewed during December and January and present copies of their curricula vitae to the three Consultants concerned in the rotation.

The three Consultants have usually agreed on the selection of the candidates for the single rotation but, in the event of disagreement, each is entitled to one first choice. Successful candidates who pass their finals take up the post on 1 August.

The medical and surgical posts offer the normal educational experiences with the added advantage that, apart from those starting on 1 August, there is a variation in starting date between four month and six month post holders, so that advice can be offered to newcomers from doctors already established with the firm. All House Offcers are supervised by an SHO or Registrar and, in addition, there is normally a Senior Registrar and Consultant in each firm.

As far as the psychiatric post is concerned, this being unique in Britain, the House Officer works in a psychiatric unit in a District General Hospital. The doctor deals with acute psychiatric in-patients and day patients and occasionally helps out in the out-patient clinic. In addition, there is one in four on call rota during which there is first responsibility for medical and psychiatric emergencies and the admission of new patients coming in after normal working hours. The House Officer is covered by a Senior House Officer or Registrar when on call. It is designed to give experience to the House Officer since, during holiday periods, the SHO or Registrar would be doing the on call work.

The House Officer is responsible for clerking of new patients, supervising medical care and participating in ward rounds, case conferences and individual and group treatments. There is also opportunity to participate in ward staff support groups and multidisciplinary team discussions. In addition to the formal review by the Postgraduate Dean, each House Officer has been giving informal feedback about the post at the end of the 12 months.

\section{Outcome}

Information has been sought concerning the pattern of further careers of the 21 House Officers who have completed their pre-registration posts to date.

Of these 21 doctors, there are 10 women and 11 men. Six have definitely embarked on a career in psychiatry and eight are in vocational training schemes in general practice; the remaining seven are too early in their careers or have not made a definite decision. Of those taking up psychiatry, three have passed the Membership Examination of the Royal College of Psychiatrists while the fourth has passed the Preliminary Test. Two of the general practitioner trainees have passed the DRCOG and one of these has also obtained Membership of the Royal College of General Practitioners.

In their comments about the rotation, several doctors mentioned that the medical post was by far and away the hardest with long hours, little sleep and a heavy caseload. The surgical posts were relatively easy and straightforward while the psychiatry, although not physically taxing, was emotionally draining and brought about greater self awareness and psychological understanding.

Other points mentioned were the advantages of having an organised year, rather than having to search round for a job after two or three months, the stability in one hospital so that one quickly got to know all the various departments, and the feeling of participating in a new venture. Several of the replies referred to the fact that it proved a good talking point at interviews and people tended to be interested in the scheme; candidates felt that it offered them an advantage in the competitive situation of job hunting, whether in psychiatry or in other branches of medicine.

On the negative side, there has been a fear of missing out on adequate experience in medicine and surgery. A particular aspect of that was House Officers who did the first limb of the rotation in psychiatry so that they missed the general support offered to newly appointed House Officers in medicine or surgery and, by the time they 
moved into one of the other posts, the remaining House Officers had been around for four months and were oldstagers.

The length of experience is a more difficult issue. In psychiatry it is probably valuable to have a considerable degree of medical experience and, to a lesser extent, surgical experience. This, however, is not the function of the preregistration House Officer post. That is intended to be an educational activity allowing newly qualified doctors an opportunity to try themselves out in practical conditions under supervision of senior staff. In that sense, it does not matter overmuch which particular branch of medicine or of surgery is experienced provided that the principles of general medicine and general surgery are taught. The reality is that many six months posts are, in fact, three months of general medicine and three months of a specialised area and the same is true of surgery. Therefore the argument that the candidate has inadequate experience in general medicine or general surgery is incorrect; they actually have a month more than a number of their colleagues who spend time in specialties which have few or no acute medical or surgical admissions and where much of the work is a routine clerking and arranging for various investigations. The solution to the problem of adequate medical and surgical experience lies more in the field of an extension of the pre-registration posts or embarking on a wider range of general professional training, as is under discussion in the Education Committee of the General Medical Council.

Without exception, the House Officers recommended this type of post in principle, although there were reservations about extending it widely into areas of psychiatry which might not provide suitable experience for this level of House Officer.

The General Medical Council has recommended wider experimentation in the organisation of pre-registration posts. There have been two reports of the incorporation of general practice into the pre-registration year ${ }^{3.4}$ and a review of the whole topic at an ASME meeting ${ }^{5}$ demonstrated that the present arrangements were far from satisfactory and that opportunities for experimentation had not been pursued. Psychiatrists working in general hospitals might do well to approach their medical and surgical colleagues and the Postgraduate Dean to examine the possibilities of setting up similar rotations.

\section{REFERENCES}

${ }^{1}$ Recommendations on Basic Medical Education (1980) London: General Medical Council (Education Committee).

${ }^{2}$ SeAGER, C. P. (1985) Initiatives in the pre-registration year. British Medical Journal, 291, 251.

${ }^{3}$ Freeman, G. K. \& Coles, C. R. (1982) The pre-registration houseman in general practice. British Medical Journal, 284, 1379-1383.

${ }^{4}$ Harris, C. M., Dudley, H. A. F., Jarman, B. \& Kidner, P. H. (1985) Pre-registration rotation including general practice at St Mary's Hospital Medical School, British Medical Journal, 290, 1811-1813.

${ }^{5}$ Rhodes, P. (1983) The Pre-registration Year. Dundee: ASME Occasional Publication 2.

\section{Psychosocial Rehabilitation International (PRI)}

This new international organisation was founded under its present name in October 1986 at a world congress in Vienne, France following two planning meetings in April 1979 and January 1980 at the headquarters or the World Health Organization in Geneva. It had its roots in a longfelt need by workers in the field of mental health that rehabilitation of the mentally ill and psychosocial aspects of rehabilitation of all illnesses required a special organisation. Its aim is to improve the quality of life of individuals and families throughout the world affected by disabling mental illnesses. At the final organisational session on 18 October 1986 participants adopted a Declaration of Vienne on the Rights of the Mentally III, provisionally adopted a draft constitution, and elected an Executive Board with membership from many countries. The Board decided to convene the next world congress in 1989 and venues are being considered. Membership is invited and further details are available from: Dr Gaston Harnois, Secretary-General, Psychosocial Rehabilitation International (PRI), Hôpital Douglas, 68-75 Blvd. LaSalle, Verdun, Quebec 4H4 IR3, Canada.

\section{Action on Dementia}

The Mental Health Foundation has recently awarded the Alzheimer's Disease Society a grant for two years to enable it to appoint a Co-ordinator to set up a project to be called Action on Dementia. This project will bring together representatives of professional and voluntary organisations and individual experts to form a campaigning body committed to improving and extending the services to dementia sufferers and their carers. It aims to draw attention to the nature of dementia and the needs of sufferers and carers; press statutory and voluntary bodies for the urgent implementation of recommendations on services for this group; identify and publicise models of good practice and provide a multidisciplinary forum to share ideas, information and research on how to provide the best possible care for individual sufferers and carers. It follows the success of Scottish Action on Dementia, launched in 1985 and part funded by the Mental Health Foundation. (Dementia in Scotland: priorities for care, strategies for change, a report from Scottish Action on Dementia, January 1986 is available from Scottish Action on Dementia, 33 Castle Street, Edinburgh EH2 3DN, price $£ 1.00$, including postage and packing). 